\title{
Farelo de Soja, Soja Integral Macerada e Soja Micronizada na Alimentação de Leitões Desmamados aos 21 Dias de Idade ${ }^{1}$
}

\author{
Messias Alves da Trindade Neto², Hacy Pinto Barbosa², Izabel Marin Petelincar ${ }^{3}$
}

\begin{abstract}
RESUMO - Distribuíram-se 72 leitões desmamados aos 21 dias de idade, com peso de 5,01 \pm 0,90 kg, em delineamento de blocos ao acaso, com seis repetições e quatro animais por unidade experimental. Os tratamentos utilizados foram rações com as seguintes fontes protéicas: farelo de soja, soja integral macerada e soja micronizada. Forneceram-se as dietas do desmame aos 42 dias (fase inicial-1) e de 43 a 56 dias (fase inicial-2) de idade. Os efeitos residuais dos tratamentos aplicados durante o período de creche foram avaliados nas fases de crescimento e terminação. Considerando as fases inicial-1, inicial-2 e o período total de permanência na creche, os leitões que receberam farelo de soja mostraram desempenho superior aos demais e aqueles que consumiram a soja integral macerada, maior ganho de peso em relação aos alimentados com soja micronizada na fase inicial-1 e no período total. Quanto ao peso, os benefícios no fim do período de creche puderam ser observados nas fases de crescimento e terminação. Os animais que consumiram farelo de soja atingiram pesos esperados de 50 e $95 \mathrm{~kg}$ em menor tempo, em comparação àqueles que consumiram soja micronizada. Em relação aos animais que haviam recebido as dietas com soja micronizada, a redução do período foi de cinco dias na fase de crescimento, seis na fase de terminação e 11 dias para atingir $95 \mathrm{~kg}$ de peso vivo, comparados àqueles que receberam farelo de soja. Entre as fontes protéicas provenientes da soja, o farelo é o mais indicado na alimentação de leitões após o desmame. A soja integral macerada deve ser avaliada como alternativa econômica em substituição ao farelo de soja.
\end{abstract}

Palavras-chave: creche, crescimento, desempenho subseqüente, terminação

\section{Soybean Meal, Macerated Full Fat Soybean and Micronized Soybean on Weaned Piglets Fed at 21 Days of Age}

\begin{abstract}
Seventy two piglets weaned at 21 days of age with live weight of $5.01 \pm 0.90 \mathrm{~kg}$ were allotted to a randomized block design, replicated six times with four animals per experimental unit. The treatments were constituted of diets with the following protein sources: soybean meal, macerated full fat soybean and micronized soybean. The diets were fed from weaning to 42 days (initial-1 phase) and from 43 to 56 days of age (initial-2 phase). The residual effects of the treatments provided in the nursery period were evaluated in the growing and finishing phases. Considering the initial-1, initial-2 and total period of permanence in the nursery, the piglets fed diet with soybean meal showed higher performance than the others, and the ones fed macerated full fat soybean, higher weight gain than those fed micronized soybean in initial-1 phase and total period. The benefits on weight during nursery phase should be observed in the growing and finishing phases. The animals fed soybean meal reached the ideal weights of 50 and $95 \mathrm{~kg}$ at minor age, compared to those fed micronized soybean. In relation to those fed diet with micronized soybean, the reduction of period was of 5 days in the growing phase, 6 days in the finishing phase e 11 days to reach $95 \mathrm{~kg}$ of live weight, compared to those fed soybean meal. Among the protein sources, the soybean meal is more indicated in the piglets feeding after weaning. The macerated full fat soybean must be evaluated as an economic alternative in the replacement of soybean meal.
\end{abstract}

Key Words: nursery, growing, subsequent performance, finishing

\section{Introdução}

A soja em grão, por ser a principal fonte protéica disponível para as dietas dos suínos, vem sendo estudada sob diferentes formas de processamento, na alimentação de leitões após a desmama. Os processamentos desenvolvidos para a soja, além da extração de óleo na obtenção do farelo, têm priorizado o aproveitamento do valor energético do grão integral. No processamento térmico da soja, busca-se minimizar a ação dos fatores antinutricionais sobre o trato digestivo, atenuando os efeitos prejudiciais no desempenho dos leitões, durante os períodos iniciais do crescimento após o desmame. Constata-se, porém, que os resultados experimentais obtidos, com a utilização da soja processada em dietas para leitões após o desmame, são divergentes.

\footnotetext{
1 Projeto financiado pela FAPESP.

2 Instituto de Zootecnia, Caixa Postal 60, 13460-000, Nova Odessa (SP). E.mail: trindadeneto@izsp.br

3 Engenheira-Agrônoma, Instituto de Zootecnia.
} 
Em grande parte das avaliações dos derivados da soja - produtos comerciais ou não - verificou-se a inviabilidade de uso nas dietas iniciais de leitões desmamados entre a segunda e a quarta semana de idade. Li et al. (1990) comprovaram os efeitos deletérios do farelo de soja no trato digestivo e as implicações negativas no desempenho de leitões desmamados aos 21 dias de idade, quando substituíram a proteína láctea dietética. Os resultados de Moreira et al. (1994), Barbosa et al. (1999a,b) e Soares et al. (2000) ratificaram o pior desempenho dos leitões submetidos às dietas que continham soja integral extrusada, comparadas àquelas com farelo de soja. Embora as respostas obtidas por Soares et al. (2000) não apresentassem diferenças estatísticas, o ganho de peso dos leitões alimentados com farelo de soja foi $15 \%$ (média de $63 \mathrm{~g} / \mathrm{dia}$ ) superior aos que consumiram soja integral extrusada; situação a ser considerada, uma vez que no fím do período de creche essa diferença pode atingir valores acumulados superiores a dois quilos por animal.

Não obstante, por intermédio da extrusão, Friesen et al. (1993) verificaram que a soja e os subprodutos, quando comparados ao farelo de soja, propiciaram desempenho semelhante aos leitões. Utilizando método industrial, Sohn et al. (1994) constataram que o processamento da soja integral permitiu aos leitões desmamados aos 21 dias de idade desempenho semelhante àqueles alimentados com produtos lácteos. Com o cozimento da soja integral, Kaankuka et al. (1996) obtiveram resultados satisfatórios em relação ao uso do farelo de soja para leitões em idade de creche.

Durante a fase de creche, avaliaram-se os efeitos das fontes protéicas, provenientes da soja em grão, no desempenho dos leitões e, nas fases subseqüentes, a provável ação residual dos tratamentos sobre as mesmas variáveis, respectivos tempos gastos para atingir 50 e $95 \mathrm{~kg}$ de peso vivo e a idade à terminação.

\section{Material e Métodos}

Utilizaram-se 72 leitões mestiços, provenientes de cruzamentos entre reprodutores e matrizes comerciais, machos castrados e fêmeas, desmamados aos 21 dias de idade, com peso inicial de 5,01 $\pm 0,90 \mathrm{~kg}$, distribuídos em delineamento de blocos ao acaso. Para cada tratamento havia seis repetições e a unidade experimental constituiu-se de quatro animais (dois de cada sexo).

Consideraram-se as seguintes fases de creche: inicial-1 - do desmame aos 42 dias; inicial-2 - de 43 a 56 dias, e período total ( 35 dias). Para acompanhamento do desempenho subseqüente, nas fases de crescimento e terminação, os animais foram alojados dois a dois $\left(1 / \mathrm{m}^{2}\right)$ dividindo-se a parcela original em duas novas unidades experimentais, cada uma com dois machos castrados e duas fêmeas.

A unidade de creche, do Instituto de Zootecnia, consistia em um galpão de alvenaria, com janelas (tipo vitraux) dispostas nas laterais, baias suspensas, piso plástico vazado e divisórias metálicas com grades. Cada baia possuía aquecedor, comedouro semi-automático e bebedouro do tipo chupeta. Terminado o período de creche, os leitões foram transferidos para a unidade de crescimento e terminação, em sítio segregado à cerca de 45 quilômetros. Na nova unidade, os suínos foram alojados em baias com piso cimentado, providas de divisórias com barras de aço, bebedouro chupeta e comedouro para abastecimento diário.

As fontes protéicas estudadas foram o farelo de soja, soja integral macerada e soja micronizada (produto comercial). A soja integral macerada foi aquecida à temperatura aproximada de $120^{\circ} \mathrm{C}$, durante 40 minutos, conforme descreveu Trindade Neto et al. (1999b). Os ingredientes empregados nas dietas foram analisados no Laboratório de Bromatologia do Centro de Nutrição e Alimentação Animal do Instituto de Zootecnia. O palatabilizante (produto comercial), em $90 \%$ de matéria seca, continha o seguinte: $15,16 \%$ de proteína bruta (PB), $3.420 \mathrm{kcal} / \mathrm{kg}$ de energia metabolizável (EM - valor estimado); 0,54\% de cálcio, $0,39 \%$ de fósforo total $(\mathrm{Pt})$ e 0,12 de fósforo disponível $(\mathrm{Pd})$. Os antibióticos adicionados nas dietas foram a oxitetraciclina na fase inicial-1 e o fosfato de tilosina na inicial-2. As dietas apresentadas na Tabela 1 foram formuladas com base na digestibilidade ileal verdadeira dos ingredientes (NRC, 1998). Forneceram-se ração e água, à vontade, para os animais.

O controle do ganho de peso, a ingestão de alimentos e o cálculo da conversão alimentar foram feitos no fìm das fases inicial-1, inicial-2 e do período total. Nas etapas subseqüentes, efetuou-se o controle do desempenho ao término das fases de crescimento e terminação, quando também foram aferidos, respectivamente, o tempo (dias) gasto para os suínos atingirem 50 e 95 $\mathrm{kg}$ de peso vivo e a idade a $95 \mathrm{~kg}$.

As dietas fornecidas nas etapas subseqüentes ao período de creche foram as mesmas utilizadas na granja de origem, com os seguintes níveis nutricionais: 
Tabela 1 - Composição centesimal das dietas experimentais ( $90 \%$ de matéria seca)

Table 1 - Composition of the experimental diets (90\% dry matter)

\begin{tabular}{|c|c|c|c|c|c|c|}
\hline \multirow{2}{*}{$\begin{array}{l}\text { Ingrediente (\%) } \\
\text { Ingredient } \\
\text { Farelo de soja }\end{array}$} & \multicolumn{3}{|c|}{$\begin{array}{l}\text { Inicial-1 ( } 21 \text { a } 42 \text { dias de idade) } \\
\text { Initial-1 (from } 21 \text { to } 42 \text { days of age) }\end{array}$} & \multicolumn{3}{|c|}{$\begin{array}{l}\text { Inicial-2 ( } 43 \text { a } 56 \text { dias de idade) } \\
\text { Initial-2 (from } 43 \text { to } 56 \text { days of age) }\end{array}$} \\
\hline & 15,95 & - & - & 21,90 & - & - \\
\hline $\begin{array}{l}\text { Soja integral macerada }{ }^{1} \\
\text { Macerated full fat soybean }\end{array}$ & - & 19,70 & - & - & 26,82 & - \\
\hline $\begin{array}{l}\text { Soja micronizada } \\
\text { Micronized soybean }\end{array}$ & - & - & 21,00 & - & - & 28,80 \\
\hline $\begin{array}{l}\text { Milho comum } \\
\text { Corn grain }\end{array}$ & 50,50 & 46,00 & 45,50 & 63,00 & 58,10 & 56,30 \\
\hline $\begin{array}{l}\text { Leite em pó desnatado } \\
\text { Dried skim milk }\end{array}$ & 15,00 & 15,00 & 15,00 & 7,50 & 7,5 & 7,5 \\
\hline $\begin{array}{l}\text { Soro de leite } \\
\text { Dried whey }\end{array}$ & 10,00 & 10,00 & 10,00 & 5,00 & 5,00 & 5,00 \\
\hline $\begin{array}{l}\text { Palatabilizante } \\
\text { Palatabilizant }\end{array}$ & 6,00 & 6,00 & 6,00 & - & - & - \\
\hline $\begin{array}{l}\text { Fosfato bicálcico } \\
\text { Dicalcium phosphate }\end{array}$ & 0,85 & 0,95 & 0,74 & 0,92 & 0,82 & 0,82 \\
\hline $\begin{array}{l}\text { Calcário calcítico } \\
\text { Limestone }\end{array}$ & 0,65 & 0,62 & 0,73 & 0,71 & 0,83 & 0,80 \\
\hline $\begin{array}{l}\mathrm{L} \text {-lisina } \mathrm{HCl} \\
\text { L-lysine } \mathrm{HCl}\end{array}$ & 0,302 & 0,202 & 0,160 & 0,131 & 0,100 & 0,100 \\
\hline $\begin{array}{l}\text { DL-Metionina } \\
\text { DL-methionine }\end{array}$ & 0,106 & 0,081 & 0,067 & 0,008 & - & - \\
\hline $\begin{array}{l}\text { Premix vitamina } \\
\text { Vitamin mix }\end{array}$ & 0,40 & 0,40 & 0,40 & 0,40 & 0,40 & 0,40 \\
\hline $\begin{array}{l}\text { Premix mineral } \\
\text { Mineral mix }\end{array}$ & 0,10 & 0,10 & 0,10 & 0,10 & 0,10 & 0,10 \\
\hline $\begin{array}{l}\text { Antibiótico } \\
\text { Antibiotic }\end{array}$ & 0,03 & 0,03 & 0,03 & 0,10 & 0,10 & 0,10 \\
\hline $\begin{array}{l}\text { Sal } \\
\text { Salt }\end{array}$ & 0,10 & 0,10 & 0,10 & 0,20 & 0,20 & 0,20 \\
\hline $\begin{array}{l}\text { Óleo de soja } \\
\text { Soybean oil }\end{array}$ & 0,008 & - & - & 0,006 & - & - \\
\hline $\begin{array}{l}\text { Areia } \\
\text { Sand } \\
\text { Composição calculada } \\
\text { Calculated composition }\end{array}$ & - & 0,897 & 0,173 & 0,023 & 0,137 & - \\
\hline $\begin{array}{l}\text { Energia metabolizável }(\mathrm{kcal} / \mathrm{kg}) \\
\text { Metabolizable energy }\end{array}$ & 3299 & 3315 & 3318 & 3265 & 3405 & 3379 \\
\hline $\begin{array}{l}\text { Proteína bruta }(\%) \\
\text { Crude protein }\end{array}$ & 18,01 & 18,00 & 18,01 & 18,00 & 18,00 & 18,00 \\
\hline $\begin{array}{l}\text { Cálcio }(\%) \\
\text { Calcium }\end{array}$ & 0,80 & 0,80 & 0,80 & 0,70 & 0,70 & 0,70 \\
\hline $\begin{array}{l}\text { Fósforo total }(\%) \\
\text { Total P }\end{array}$ & 0,61 & 0,61 & 0,61 & 0,56 & 0,58 & 0,57 \\
\hline $\begin{array}{l}\text { Fósforo disponível (\%) } \\
\text { Available } P\end{array}$ & 0,40 & 0,40 & 0,40 & 0,32 & 0,32 & 0,32 \\
\hline $\begin{array}{l}\text { Lisina digestível (\%) } \\
\text { Digestible lysine }\end{array}$ & 1,19 & 1,19 & 1,19 & 1,01 & 1,01 & 1,06 \\
\hline $\begin{array}{l}\text { Met }+ \text { cis digestível (\%) } \\
\text { Digestible met }+ \text { cys }\end{array}$ & 0,68 & 0,68 & 0,68 & 0,58 & 0,61 & 0,62 \\
\hline $\begin{array}{l}\text { Trip. digestível }(\%) \\
\text { Digestible triptofan }\end{array}$ & 0,18 & 0,20 & 0,21 & 0,18 & 0,20 & 0,21 \\
\hline $\begin{array}{l}\text { Treonina digestível (\%) } \\
\text { Digestible threonine }\end{array}$ & 0,64 & 0,68 & 0,70 & 0,61 & 0,67 & 0,70 \\
\hline
\end{tabular}

${ }^{1}$ Atividade ureática $=0,02$; solubilidade protéica em $\mathrm{KOH} 0,2 \%=63,0$; inibidor de tripsina (UTI/mg de amostra) e hemaglutinina (UH/mg de amostra) não detectados.

1 Urea activity $=0.02$; protein solubility in $\mathrm{KOH} 0.2 \%=63.0$; trypsin inhibitor activity (TIU/mg) and haemagg/utinin (HU/mg), not detected.

2 kg de mistura (mix by kg): A 2.250 .000 UI; vit. $D_{3} 450.000$ UI; vit. E 4.500 mg; vit. $K_{3} 400$ mg; vit. $B_{1} 350$ mg; vit. $B_{2} 1000$ mg; vit. $B_{6} 350$ mg; vit. $\mathrm{B}_{12} 4500 \mathrm{mcg}$; Niacina (Niacin) 7500 mg; Ác. pantotênico (Pantothenic acid) 4000 mg; Ác. fólico (Pholic acid) 100 mg; Biotina (Biotin) 25 mg; Colina (Choline) $75.000 \mathrm{mg}$; Promotor de crescimento (Growth promoter) $19.000 \mathrm{mg}$; Antibiótico (Antibiotic) $16.500 \mathrm{mg}$ e Antioxidante (Anthioxidant) $25.000 \mathrm{mg}$.

3 kg de mistura (Mix by kg): Fe 80.000 mg; Cu 12.000 mg; Mn 70.000 mg; Zn 100.000 mg; I 1000 mg; Se 120 mg. 
EM 3265 e $3240 \mathrm{kcal} / \mathrm{kg}$; PB 17,5 e 15,0\%; Ca 0,60 e $0,50 \%$; Pt 0,50 e $0,40 \%$ nas fases de crescimento e terminação, respectivamente.

As análises estatísticas das variáveis experimentais foram realizadas pelo SAS (1996) e as médias, comparadas pelo teste Tukey.

$$
\mathrm{Y}_{\mathrm{ijk}}=\mu+\mathrm{F}_{\mathrm{i}}+\mathrm{Bj}+\mathrm{e}_{\mathrm{ij}}
$$

em que: $Y_{i j k}=$ constante associada a todas as observações; $\mu=$ média geral da variável; $\mathrm{F}_{\mathrm{i}}=$ efeito da fonte protéica $i$, sendo $i=1,2$ e $3 ; B_{j}=$ efeito do bloco $\mathrm{j}$, sendo $\mathrm{j}=1,2, \ldots$ e 6 ; $\mathrm{e}_{\mathrm{ijk}}=$ erro aleatório associado a cada observação.

\section{Resultados e Discussão}

Os resultados de desempenho dos leitões, durante as fases inicial-1, inicial-2 e período total de creche encontram-se na Tabela 2.

Na fase inicial-1, observou-se diferença significativa $(\mathrm{P}<0,01)$ no ganho de peso. A dieta que continha farelo de soja propiciou maior ganho de peso aos leitões, seguida daquela com soja integral macerada. Quanto ao consumo de ração não se observaram diferenças $(\mathrm{P}>0,05)$ pelo teste Tukey, ainda que os leitões submetidos à dieta com soja integral macerada e farelo de soja apresentassem, respectivamente, resultados superiores em $16 \%$ e $12 \%$ aos da soja micronizada. As diferenças $(\mathrm{P}<0,05)$ entre os tratamentos nas respostas para a conversão alimentar, caracterizaram maior eficiência dos leitões na utilização dos nutrientes da dieta que continha o farelo de soja. Comparando-se com as demais fontes protéicas estudadas, presume-se que o farelo de soja apresente menor ação deletéria no sistema e no processo digestivo do leitão, durante os primeiros 21 dias após o desmame.

Os resultados ratificaram aqueles observados por Moreira et al. (1994) e Barbosa et al. (1999a,b), os quais verificaram que a presença do farelo de soja favoreceu o desempenho dos leitões, quando comparado com outras combinações de soja integral, obtidas por diferentes processamentos, nas rações para leitões após o desmame.

Em relação à soja integral micronizada, as res-

Tabela 2 - Desempenho dos leitões durante o período de creche, segundo a fonte protéica Table 2 - Performance of piglets during the nursery phase, in function of the protein source ${ }^{1}$

\begin{tabular}{|c|c|c|c|c|}
\hline Item & $\begin{array}{l}\text { Farelo de soja } \\
\text { Soybean meal }\end{array}$ & $\begin{array}{l}\text { Soja integral macerada } \\
\text { Macerated full fat soybean }\end{array}$ & $\begin{array}{l}\text { Soja micronizada } \\
\text { Micronized soybean }\end{array}$ & $\begin{array}{l}\mathrm{CV} \\
\%\end{array}$ \\
\hline & \multicolumn{3}{|c|}{$\begin{array}{l}\text { Fase inicial-1 (de } 21 \text { a } 42 \text { dias de idade) } \\
\text { Initial phase-1 (from } 21 \text { at } 42 \text { days of age) }\end{array}$} & \\
\hline $\begin{array}{l}\text { Ganho de peso }(\mathrm{g} / \text { dia }) \\
\text { Weight gain }(g / \text { day) }\end{array}$ & $426,8^{\mathrm{A}}$ & $387,8^{\mathrm{B}}$ & $324,2^{\mathrm{C}}$ & 3,4 \\
\hline $\begin{array}{l}\text { Consumo de ração (g/dia) } \\
\text { Feed intake (g/day) }\end{array}$ & 467,8 & 483,8 & 417,8 & 9,8 \\
\hline $\begin{array}{l}\text { Conversão alimentar } \\
\text { Feed:gain ratio }\end{array}$ & $1,17^{\mathrm{a}}$ & $1,25^{\mathrm{ab}}$ & $1,29^{b}$ & 5,0 \\
\hline
\end{tabular}

Feed:gain ratio

Fase inicial-2 (de 43 a 56 dias de idade)

Ganho de peso (g/dia) Initial phase-2 (from 43 at 56 days of age)

Weight gain (g/day)

$\frac{\text { Initial phase-2 (from } 43 \text { at } 56 \text { days of age) }}{546,0^{\mathrm{AB}}}$

$551,8^{\mathrm{B}}$

Consumo de ração (g/dia)

Feed intake (g/day)

Conversão alimentar

Feed:gain ratio

$1105,4^{\mathrm{A}}$

1,72

1,78

$915,0^{\mathrm{B}}$

\begin{tabular}{|c|c|c|c|c|}
\hline \multirow[b]{2}{*}{ Ganho de peso (g/dia) } & \multicolumn{3}{|c|}{$\begin{array}{l}\text { Fase total de creche } \\
\text { Total nursery phase }\end{array}$} & \multirow[b]{2}{*}{3,2} \\
\hline & $522,6^{\mathrm{A}}$ & $463,0^{\mathrm{B}}$ & $415,2^{\mathrm{C}}$ & \\
\hline Weight gain $(g /$ day $)$ & & & & \\
\hline Consumo de ração (g/dia) & $703,8^{a}$ & $701,4^{\mathrm{a}}$ & $617,0^{b}$ & 7,6 \\
\hline $\begin{array}{l}\text { Feed intake (g/day) } \\
\text { Conversão alimentar } \\
\text { Feed:gain ratio }\end{array}$ & $1,38^{\mathrm{a}}$ & $1,51^{b}$ & $1,49^{b}$ & 5,0 \\
\hline
\end{tabular}

Médias seguidas por letras diferentes na linha, maiúsculas $(P<0,02)$ ou minúsculas $(P<0,05)$, diferem pelo teste Tukey.

Means followed by different letters, within a row, small $(P<.02)$ or capital $(P<.05)$, are different by Tukey test. 
postas obtidas neste estudo diferiram daquelas encontradas por Moreira et al. (1994), quando concluíram que o ingrediente seria tão viável quanto o farelo de soja, em dietas para leitões desmamados aos 21 dias de idade. Comparando os resultados deste experimento com os obtidos por Moreira et al. (1994), as prováveis e principais diferenças deveram-se às formas físicas da ração e aos níveis de inclusão de produtos lácteos nas dietas. No segundo caso, os autores utilizaram rações com apenas $9,5 \%$ de produtos lácteos, o que pode ter afetado o consumo de todos os tratamentos estudados. Conforme salientaram Lepine et al. (1991), independentemente do tipo de dieta, nos primeiros 21 dias após o desmame, a inclusão de produtos lácteos não deve ser inferior a 25\%; Mahan e Newton (1993) sugeriram níveis mínimos de 35 a $45 \%$.

Considerando as implicações fisiológico-digestivas do leitão no pós-demame, o nível de inclusão dos produtos lácteos, provavelmente, favoreceu a comparação entre as fontes protéicas, visto que a digestibilidade das dietas estaria menos comprometida. Conforme concluiu Li et al.(1990), a hipersensibilidade doleitão às proteínas da soja implicou pior desempenho, quando foi comparada com a láctea.

$\mathrm{Na}$ fase inicial-2, os leitões que receberam farelo de soja apresentaram maior $(\mathrm{P}<0,01)$ ganho de peso e consumo de ração, em relação aos que foram alimentados com dieta contendo soja micronizada. Quanto aos que receberam soja integral macerada, os resultados não diferiram $(\mathrm{P}>0,05)$ dos demais tratamentos, embora o ganho de peso tenha sido superior a $12 \%$ em relação àqueles alimentados com farelo de soja. Entre a soja macerada e a micronizada também não ocorreram diferenças significativas na ingestão de alimento, ainda que o consumo da primeira tenha sido $12 \%$ superior.

Os efeitos benéficos do farelo de soja sobre o desempenho dos leitões foram confirmados no período total de creche, ratificando as observações de Barbosa et al. (1999a,b) para o mesmo ingrediente, em relação à soja integral obtida com extrusão seca e úmida.

Como ressaltado na fase inicial-1, a presença e o nível de inclusão (12,5\%) dos produtos lácteos podem ter favorecido as respostas dos animais aos tratamentos experimentais de 43 a 56 dias de idade. Segundo Shields Jr. et al. (1980), a atividade enzimática do pâncreas e da mucosa intestinal aumenta da segunda para a décima semana de vida e a compatibilidade com o substrato digestivo tem impli- cações na utilização dos nutrientes e, conseqüentemente, no seu desempenho.

$\mathrm{Na}$ avaliação do período total (35 dias) de creche, constataram-se diferentes $(\mathrm{P}<0,01)$ respostas no ganho de peso dos leitões, sendo o maior e o menor ganho obtidos com o farelo de soja e a soja micronizada, respectivamente. Para o consumo de ração no período, também houve diferenças $(\mathrm{P}<0,04)$ e os resultados com as dietas que continham farelo e soja macerada foram, aproximadamente, 14\% superiores às de soja micronizada. Quanto à conversão alimentar, os melhores resultados $(\mathrm{P}<0,04)$ foram obtidos com os leitões que receberam o farelo de soja. Os resultados refletiram o desempenho médio ocorrido nas fases inicial-1 e 2, confirmando-se o melhor uso dos nutrientes dietéticos e a menor incidência dos prováveis efeitos limitantes, proporcionados pelo farelo de soja, no processo digestivo dos leitões. $\mathrm{O}$ presente estudo ratifica informações da literatura, que apontam o pior desempenho de leitões após o desmame, quando receberam dietas que continham soja integral obtidas por diferentes processos, em relação àqueles alimentados com farelo de soja (Moreira et al., 1994; Barbosa et al., 1999a,b; Soares et al., 2000). Não obstante, discordam dos resultados de Friesen et al. (1993) e Sohn et al. (1994), quando não detectaram diferenças entre subprodutos da soja e da soja integral extrusada pelo método industrial, comparando-os com produtos lácteos, para leitões desmamados aos 21 dias de idade.

Os resultados observados para a soja macerada integral, provavelmente, foram afetados pela redução da digestibilidade, decorrente do processamento térmico, visto que os valores de solubilidade protéica (63\%) estavam abaixo do recomendado. Trindade Neto et al. (1999b) estabeleceram a mesma hipótese, baseandose nas informações de Dale (1988) de que a solubilidade deveria estar entre 73 e $85 \%$ e valores abaixo caracterizariam o superaquecimento e, conseqüentemente, prejuízo no valor nutritivo do alimento.

O desempenho dos suínos nas fases de crescimento e terminação, avaliados como efeitos residuais das dietas experimentais fornecidas no período de creche, estão apresentados na Tabela 3.

As diferenças $(\mathrm{P}<0,01)$ na variável peso aos 56 dias de idade que caracterizavam os efeitos dos tratamentos, no término do período de creche, diminuíram no transcorrer da fase de crescimento. Até os animais atingirem $50 \mathrm{~kg}$ de peso vivo, observou-se o maior $(\mathrm{P}<0,06)$ ganho de peso em leitões que anterior- 


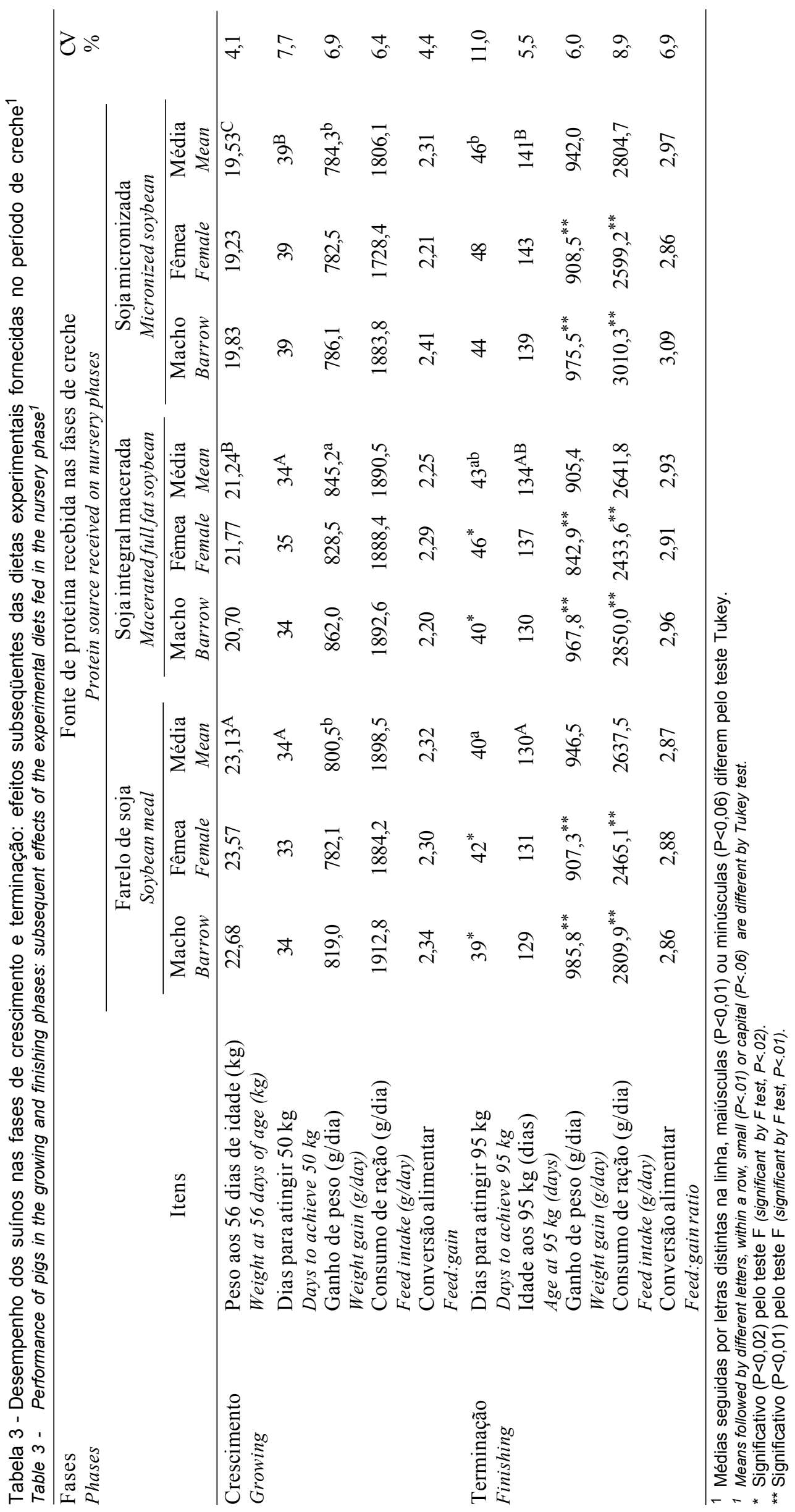


mente consumiram a soja integral macerada; para os demais, os resultados foram semelhantes $(\mathrm{P}>0,05)$. Em relação ao consumo e a conversão alimentar as diferenças não foram significativas $(\mathrm{P}>0,05)$.

Quanto ao número de dias para os suínos atingirem o peso esperado no fim da fase de crescimento, as pequenas diferenças acumuladas no desempenho tornaram-se significativas $(\mathrm{P}<0,01)$. Na média, o tempo gasto foi menor em cinco dias para os suínos que consumiram o farelo de soja e a soja integral macerada durante a fase de creche. A redução do período de crescimento correspondeu, aproximadamente, a $9 \mathrm{~kg}$ de ração não consumida por animal, o que deve ser avaliado no contexto econômico.

Os prováveis efeitos residuais dos tratamentos aplicados nas fases de creche não foram confirmados $(\mathrm{P}>0,05)$, durante a fase de terminação, nas seguintes variáveis: ganho de peso, consumo de ração e conversão alimentar dos suínos. Nas variáveis ganho e consumo, destacou-se apenas o efeito $(\mathrm{P}<0,01)$ de sexo, sendo os maiores valores observados para os machos castrados. Com relação ao número de dias para atingir $95 \mathrm{~kg}$, os suínos que haviam consumido o farelo de soja e a soja integral macerada reduziram o tempo em seis e três dias, respectivamente, em relação àqueles que haviam recebido a dieta com soja micronizada no período de creche. Na idade de abate, as respectivas diferenças foram de 11 e 7 dias, correspondendo à economia média de ração de $26 \mathrm{~kg}$ para os animais que receberam farelo de soja e $17 \mathrm{~kg}$ para aqueles alimentados com soja integral macerada.

Em grande parte dos estudos de nutrição e alimentação com leitões após o desmame, nas fases de creche, desconsidera-se o desempenho subseqüente até a terminação. No presente estudo, constatou-se que, ao longo do tempo, o acumulado das diferenças não significativas, sob o critério estatístico, no ganho de peso, permitiu expressiva redução no número de dias gastos para o suíno atingir o peso estipulado no abate. Conforme Tokach et al. (1995), as implicações dietéticas do período de creche devem ser consideradas nos estágios subseqüentes até a terminação, sugerindo que se avalie o impacto individual ou do conjunto dos ingredientes na viabilidade econômica da dieta utilizada anteriormente. Os autores confirmaram que os efeitos benéficos da dieta fornecida, na fase de creche, poderiam refletir na terminação. Enfatizando o aproveitamento do potencial genético do suíno, Schinckel e Lange (1996) destacaram a importância da correta avaliação do desempenho durante crescimento, visto que o significativo aumento de massa muscular destaca-se a partir do nascimento até 45 a $65 \mathrm{~kg}$ de peso vivo. Trindade Neto et al. (1999a) ratificaram essas observações, quando ao utilizarem diferentes dietas nas fases de creche, constataram diferenças no ganho de peso durante a fase de crescimento e na idade final à terminação.

Os efeitos acumulados dos tratamentos aplicados durante o período de creche implicaram em alteração no tempo de permanência dos suínos nas fases de crescimento e terminação. Com base no consumo diário e no número de dias para os animais atingirem o peso final esperado em cada uma das fases, aconselha-se avaliar o custo da alimentação e a viabilidade ou não de uso dos ingredientes alternativos. Ao aferir a idade dos suínos ao peso de abate, o uso da soja integral macerada não teve implicações negativas no seu desempenho, caracterizando-se como provável alternativa econômica na alimentação dos leitões após o desmame. Porém, Trindade Neto et al. (1999b) recomendaram novos estudos com a soja macerada, destacando-se a importância na uniformização do processamento térmico e, conseqüentemente, no controle de qualidade do produto final.

Baseando-se em resultados da literatura e os encontrados no experimento, a usual aplicação de alguns testes estatísticos na comparação de médias de desempenho deve ser bem avaliada, sobretudo ao se considerar o fator produtividade.

\section{Conclusões}

Das fontes protéicas provenientes da soja, o farelo foi a mais indicada na alimentação de leitões nas fases de creche.

Devidamente processada, a soja integral macerada deve ser estudada como alternativa econômica em substituição ao farelo de soja.

Acumuladas, as pequenas diferenças no ganho de peso diário podem implicar redução significativa do número de dias para os suínos atingirem o peso de abate. 


\section{Literatura Citada}

BARBOSA, H.P.; TRINDADE NETO, M.A.; SORDI, I.M.P. et al. Efeitos dos processamentos do milho comum e da soja integral no desempenho de leitões desmamados aos 21 dias de idade. Boletim da Indústria Animal, v.56, n.1, p.59-66, 1999a.

BARBOSA, H.P.; TRINDADE NETO, M.A.; SORDI, I.M.P. et al. Efeitos dos processamentos do milho comum e da soja integral no desempenho de leitões desmamados aos 28 dias de idade. Boletim da Indústria Animal, v.56, n.1, p.67-73, 1999b.

DALE, N. Solubilidad de la proteína: indicador del procesado de la harina de soya. Avicultura Profesional, v.5, n.4, p.122$126,1988$.

FRIESEN, K.G. et al. The effects of moist extrusion of soy products on growth performance and nutrient utilization in the early-weaned pig. Journal of Animal Science, v.71, n.8, p.2099-2109, 1993.

KAANKUKA, F.G.; BALOGUN, T.F.; TEGBE, T.S.B. Effects of duration of cooking of full-fat soya beans on prodinate andysis, levels of antinutritional factors, and digestibility by weanling pigs. Animal Feeding Science and Techonology, v.62, n.2/4, p.229-237, 1996.

LEPINE, A.J.; MAHAN, D.C.; CHUNG, Y.K. Growth performance of weanling pigs fed corn-soybean meal diets with or without dried whey at various L-lysine-HCl levels. Journal of Animal Science, v.69, n.5, p.2026-2032, 1991.

LI, F.D.; NELSSEN, J.L.; REDDY, P.G. et al. Transient hypersensitivity to soybean meal in the early-weaned pig. Journal of Animal Science, v.68, n.6, p.1790-1799, 1990.

MAHAN, D.C.; NEWTON, E.A. Evaluation of feed grains with dried skim milk and added carbohydrate sources on wealing pig performance. Journal of Animal Science, v.71, n.12, p.3376-3382, 1993.

MOREIRA, I.; ROSTAGNO, H.S.; SILVA, M.A. et al. Uso da soja processada a calor na alimentação de leitões de 21 a 42 dias de idade. Revista da Sociedade Brasileira de Zootecnia, v.23, n.1, p.57-64, 1994.

NATIONAL RESEARCH COUNCIL - NRC. Nutrients requirements of swine. 10.ed. Washington: National Academy of Science, 1998. 189p.
SCHINCKEL, A.P.; LANGE, C.F.M. Characterization of growth parameters need as imputs for pig growth models. Journal of Animal Science, v.74, n.8, p.2021-2036, 1996.

SHIELDS Jr., RG.; EKSTROM, K.E.; MAHAN, D.C. Effect of weaning age and feeding method on digestive enzyme development in swine from birth to ten weeks. Journal of Animal Science, v.50, n.2, p.257-265, 1980.

SAS INSTITUTE - Statistical Analysis System Institute. SAS user's guide: statistics. Version 6.12, Cary: 1996.

SOARES, J.L.; DONZELE, J.L.; OLIVEIRA, R.F.M. et al. Soja integral processada (fermentada e extrusada) e farelo de soja em substituição ao leite em pó em dieta de leitões desmamados aos 14 dias de idade. Revista Brasileira de Zootecnia, v.29, n.4, p.1153-1161, 2000.

SOHN, K.S.; MAXWELL, C.V.; BUCHANAN, D.S. et al. Improved soybean protein sources for early-weaned pigs. Effects on performance and total tract amino acid digestibility. Journal of Animal Science, v.72, n.3, p.622-630, 1994.

TOKACH, M.D.; PETTIGREW, J.E.; JOHNSTON, L.J. et al. Effect of adding fat and (or) milk products to the weanling pig diet on performance in nursery and subsequent growfinishing stages. Journal of Animal Science, v.73, n.11, p.3358-3368, 1995.

TRINDADE NETO, M.A.; BARBOSA, H.P.; DE SORDI, I.M.P. et al. Dietas contendo milho pré-gelatinizado e níveis protéicos para leitões desmamados aos 19 dias de idade. In: REUNIÃO ANUAL DA SOCIEDADE BRASILEIRA DE ZOOTECNIA, 36, 1999, Porto Alegre. Anais... Porto Alegre: Sociedade Brasileira de Zootecnia, 1999a. (CD)

TRINDADE NETO, M.A.; BARBOSA, H.P.; DE SORDI, I.M.P. et al. Maceração e tempo de aquecimento na qualidade biológica da soja integral para suínos em fase de crescimento. Boletim da Indústria Animal, v.56, n.1, p.53-58, 1999 b.

Recebido em: 05/04/01 Aceito em: 10/08/01 